\title{
Sensory Process
}

National Cancer Institute

\section{Source}

National Cancer Institute. Sensory Process. NCI Thesaurus. Code C19989.

Processes that involve and promote the transfer or transmission of stimulatory (sensory) information from the periphery to more central organized structures and mechanisms involved in processing information. $(\mathrm{NCl})$ 